\title{
Influence of glyceryl trinitrate during supine and upright exercise in patients with angina pectoris ${ }^{1}$
}

\author{
U. THADANI ${ }^{2}$ AND JOHN O. PARKER \\ From the Department of Medicine, Queen's University, Kingston, Ontario, Canada
}

SUMMARY The clinical, electrocardiographic, and circulatory effects of $0.6 \mathrm{mg}$ sublingual glyceryl trinitrate were studied at rest and during treadmill and supine bicycle exercise in 16 patients with angina pectoris. Before glyceryl trinitrate, all patients experienced angina during both exercise periods. However, the heart rate and rate pressure product at angina were higher during treadmill than during supine bicycle exercise. This is considered to be the result of diminished left ventricular volume and oxygen requirements in the upright posture.

At rest after glyceryl trinitrate, systolic blood pressure fell and heart rate rose in each posture, the effects being more pronounced in the standing position. During exercise, when the rate pressure product at the onset of angina before glyceryl trinitrate was compared with the rate pressure product at the same work load after glyceryl trinitrate, there was no significant difference in either position (treadmill, $192 \pm 10$ vs $203 \pm 9$; supine, $185 \pm 9$ vs $182 \pm 8 \mathrm{mmHg} / \mathrm{min} \times 10^{-2}$ ). However, in comparison with the control values before glyceryl trinitrate, exercise duration to angina after glyceryl trinitrate increased significantly in each posture. The rate pressure product at angina after glyceryl trinitrate increased significantly in comparison with the rate pressure product at angina during the control studies in each posture. The improvement in exercise tolerance and increase in rate pressure product after glyceryl trinitrate were similar during both upright and supine exercise. This could be interpreted as evidence for the predominant influence of glyceryl trinitrate on coronay perfusion but it is possible that similar changes in ventricular volume during exercise occurred in both positions.

Patients with angina pectoris have better exercise tolerance and achieve higher rate pressure products in the upright than in the supine posture (Lecerof, 1971 ; Bygdeman and Wahren, 1974). This probably reflects reduced left ventricular volume with resultant decrease in wall tension and myocardial oxygen requirements for any given rate pressure product in the upright posture. This is supported by the observation that left ventricular filling pressures during exertional angina are lower during upright than during supine exercise (Thadani et al., 1977). Glyceryl trinitrate, by its venous and arteriolar effects (Mason and Braunwald, 1965), reduces left ventricular volume (Burggraf and Parker, 1974) which should be more pronounced in the upright position. Thus, one might expect that

\footnotetext{
'Supported by Grants-in-Aid from the Ontario Heart Foundation and the Medical Research Council of Canada.

${ }^{2} \mathrm{Dr}$ Thadani is a Research Fellow of the Ontario Heart Foundation.
}

Received for publication 30 March 1978 in patients with angina pectoris the administration of glyceryl trinitrate would result in greater improvement in exercise tolerance in the upright than in the supine posture. The present investigation was designed to study the influence of glyceryl trinitrate on exercise tolerance and circulatory changes during upright and supine exercise in patients with angina pectoris.

\section{Methods}

Sixteen male patients, aged 38 to 62 years (average 50 years), with uncomplicated, stable exerciseinduced angina pectoris were studied. None had suffered a myocardial infarction, were hypertensive, or had clinical or radiological evidence of cardiac enlargement or failure. The history of angina ranged from 6 months to 7 years (average 18 months) and was induced solely and repeatedly by exercise in all patients. None suffered from nocturnal or emotionally provoked angina. None was taking drugs other than sublingual glyceryl trinitrate and the. 
latter was discontinued for at least 24 hours before these studies.

The resting electrocardiogram was normal in all patients, but during exercise all developed ischaemic ST segments characterised by horizontal or downsloping ST segment depression, $0.1 \mathrm{mV}$ or more of at least 0.08 seconds duration, in modified lead V5. Informed consent was obtained from each patient.

During preliminary studies, 24 to 48 hours before the definitive investigations, each patient walked on a motor driven treadmill employing the Bruce's multistage procedure (Bruce, 1971). The patients were instructed to indicate the point at which definite chest pain $\left(\mathbf{P}_{1}\right)$ occurred and the point when the pain became of moderate intensity $\left(\mathrm{P}_{2}\right)$, at which point exercise was discontinued. From these observations, patients who experienced chest pain by the end of stage 2 or the beginning of stage 3 during treadmill exercise were selected for further studies. Depending on the response during treadmill exercise, the initial workload on the bicycle ergometer was chosen and increased at 3-minute intervals aiming to induce chest pain between 4 and 7 minutes of exercise. A record of this was made and the same workloads used in the definitive studies. Such strict criteria for selection were considered necessary in order to assess the influence of posture and sublingual glyceryl trinitrate in these patients.

Precautions were taken to control factors which might have produced changes in exercise tolerance. The laboratory temperature was $20-22^{\circ} \mathrm{C}$, and the patient's apprehension was reduced by familiarisation with the techniques and staff. The studies were performed each morning at the same time, in a fasting state with premedication. Patients did not :smoke for 2 hours before or during the study.
In each posture, control observations were made at rest and during two periods of exercise, separated by 30 minutes (control studies 1 and 2). Each study consisted of observations at rest over a 5-minute period followed by multistage exercise. After a further 30-minute rest period, patients were given $0.6 \mathrm{mg}$ sublingual glyceryl trinitrate and observations were made at rest for 5 minutes and the exercise test was repeated (study 3 ). The end-point during the control studies was moderate angina $\left(\mathbf{P}_{2}\right)$. After glyceryl trinitrate, attempts were made to continue exercise to $P_{2}$, but in some patients fatigue necessitated discontinuation of exercise before this end-point.

Modified lead V5 of the electrocardiogram was monitored on an oscilloscope throughout the study and records were taken on a standard electrocardiograph machine at a paper speed of $25 \mathrm{~mm} / \mathrm{s}$ at 1-minute intervals for the 5-minute rest period and during exercise. Further records were taken at $\mathbf{P}_{1}$ and $P_{2}$. The heart rate and ST segment depression in 10 consecutive beats were measured from the electrocardiogram. The blood pressure was measured by a sphygmomanometer at 1-minute intervals at rest and during exercise and also at $P_{1}$ and $\mathrm{P}_{2}$. Detailed records of the exact time of onset of $P_{1}$ and $P_{2}$ were made separately. The rate pressure product in $\mathrm{mmHg} / \mathrm{min} \times 10^{-2}$ was calculated as the product of systolic arterial blood pressure and heart rate $\times 10^{-2}$.

The order of exercise was randomised. Only one form of exercise was performed on a given day; patients were brought back on the next day and studies performed in the remaining posture.

Statistical analysis of the data was carried out using paired Student's $t$ test or ordinary t test. Subsequent coronary angiography was carried out

Table 1 Summary of circulatory and electrocardiographic data during two control studies

\begin{tabular}{|c|c|c|c|c|c|}
\hline \multirow[t]{2}{*}{ State } & \multirow[t]{2}{*}{$\begin{array}{l}\text { Heart rate } \\
\text { (beats } / \text { min) }\end{array}$} & \multicolumn{2}{|c|}{$\begin{array}{l}\text { Blood pressure } \\
(m m H g)\end{array}$} & \multirow[t]{2}{*}{$\begin{array}{l}\text { Rate pressure product } \\
\left(\mathrm{mmHg} / \mathrm{min} \times 10^{-2}\right)\end{array}$} & \multirow[t]{2}{*}{$\underset{(\mathrm{mm})}{E C G} S T$ depression } \\
\hline & & Systolic & Diastolic & & \\
\hline $\begin{array}{l}\text { Standing } \\
C_{1} \text { Rest } \\
C_{1} \text { Ex } P_{1} \\
C_{1} \text { Ex } P_{2} \\
C_{2} \text { Rest } \\
C_{2} \text { Ex } P_{1} \\
C_{2} \text { Ex } P_{2} \\
\text { Supine }\end{array}$ & $\begin{array}{r}83 \pm 3 \\
125 \pm 3 \\
133 \pm 3 \\
84 \pm 3 \\
120 \pm 6 \\
134 \pm 4\end{array}$ & $\begin{array}{l}127 \pm 3 \\
164 \pm 5 \\
170 \pm 5 \\
123 \pm 7 \\
159 \pm 5 \\
166 \pm 6\end{array}$ & $\begin{array}{l}85 \pm 2 \\
79 \pm 3 \\
79 \pm 3 \\
84 \pm 2 \\
78 \pm 3 \\
78 \pm 2\end{array}$ & $\begin{array}{l}106 \pm 5 \\
207 \pm 8 \\
227 \pm 10 \\
104 \pm 5 \\
200 \pm 9 \\
223 \pm 11\end{array}$ & $\begin{array}{l}0.0 \pm 0.0 \\
1.1 \pm 0.1 \\
1.7 \pm 0.1 \\
0.0 \pm 0.0 \\
1.1 \pm 0.1 \\
1.5 \pm 0.1\end{array}$ \\
\hline $\begin{array}{l}C_{1} \text { Rest } \\
C_{1} \text { Ex } P_{1} \\
C_{1} \text { Ex } P_{2} \\
C_{2} \text { Rest } \\
C_{2} \text { Ex } P_{1} \\
C_{2} \text { Ex } P_{2}\end{array}$ & $\begin{array}{r}72 \pm 2 \\
109 \pm 4 \\
113 \pm 4 \\
74 \pm 3 \\
113 \pm 4 \\
115 \pm 4\end{array}$ & $\begin{array}{l}126 \pm 3 \\
160 \pm 4 \\
166 \pm 5 \\
125 \pm 3 \\
162 \pm 4 \\
168 \pm 5\end{array}$ & $\begin{array}{l}80 \pm 2 \\
86 \pm 2 \\
86 \pm 3 \\
81 \pm 2 \\
85 \pm 3 \\
84 \pm 3\end{array}$ & $\begin{aligned} 90 & \pm 4 \\
179 & \pm 8 \\
187 & \pm 10 \\
91 & \pm 4 \\
185 & \pm 8 \\
193 & \pm 10\end{aligned}$ & $\begin{array}{l}0.0 \pm 0.0 \\
1.3 \pm 0.1 \\
1.3 \pm 0.1 \\
0.0 \pm 0.0 \\
1.2 \pm 0.1 \\
1.2 \pm 0.1\end{array}$ \\
\hline
\end{tabular}

Data presented as mean \pm standard error of the mean.

Abbreviations: $C_{1}$, control study $1 ; C_{2}$, control study $2 ;$ Ex, exercise; $P_{1}$, onset of chest pain; $P_{2}$, moderately severe chest pain. 


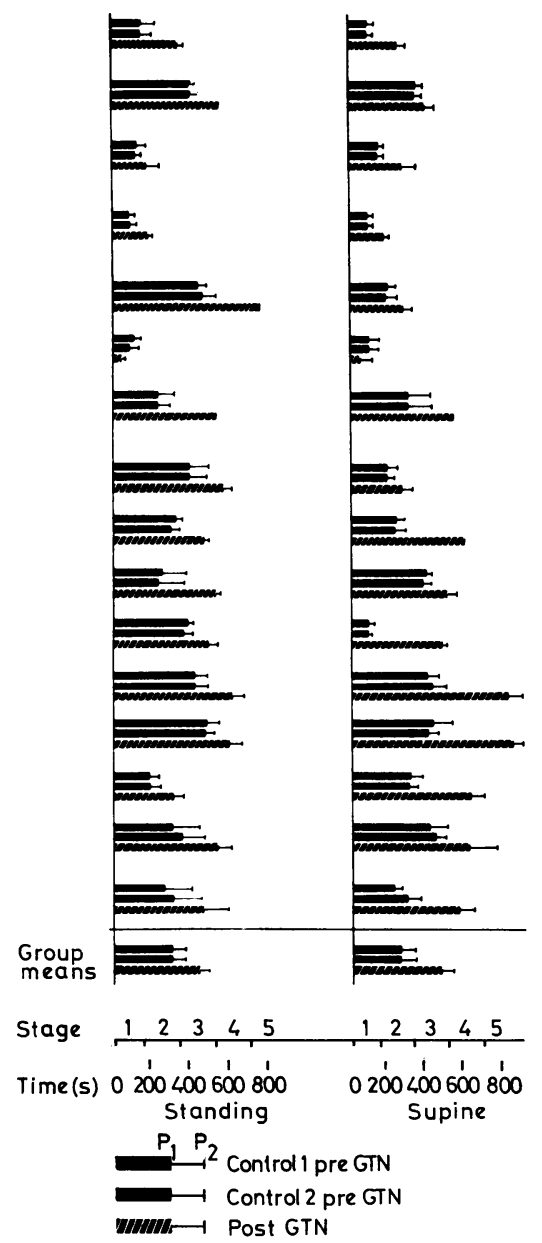

Fig. 1 Individual and group mean values for duration of exercise before and after administration of glyceryl trinitrate. The duration of exercise to the onset of chest pain $\left(P_{1}\right)$ and when the pain became of moderate severity $\left(P_{2}\right)$ increased significantly after glyceryl trinitrate in both the standing and supine postures.

in 15 of the 16 patients and showed significant (more than $75 \%$ ) obstructive disease of one or more coronary arteries.

\section{Results}

CONTROL STUDIES (Table 1)

At rest, heart rate, systolic and diastolic blood pressures, and rate pressure product were similar in the same posture during the 2 control studies. All patients experienced mild $\left(\mathbf{P}_{1}\right)$ and moderate $\left(\mathbf{P}_{2}\right)$ chest pain and developed significant ST segment depression during exercise in the standing and supine positions. In each patient, in the same posture, the duration of exercise to $P_{1}$ and $P_{2}$ during the 2 control studies was similar (Fig. 1). Similarly, at both $P_{1}$ and $P_{2}$ the individual and group values for ST segment depression, heart rate, systolic and diastolic blood pressures, and rate pressure product during the 2 control periods were similar. In view of these observations, the average of the values obtained during the 2 control periods has been used for subsequent comparison (Table 2).

At rest, the average heart rate in the standing ( $83 \pm 3$ beats $/ \mathrm{min}$, mean $\pm \mathrm{SE}$ ) position was higher than in the supine posture ( $73 \pm 3$ beats $/ \mathrm{min})$ $(P<0.05)$; systolic and diastolic blood pressure in the 2 positions were similar. The resting rate pressure product in the standing position (105 \pm $5 \mathrm{mmHg} / \mathrm{min} \times 10^{-2}$ ) was higher than in the supine position $\left(89 \pm 4 \mathrm{mmHg} / \mathrm{min} \times 10^{-2}\right)$ $(\mathrm{P}<0.05)$.

During exercise at both $P_{1}$ and $P_{2}$, the heart rate during treadmill exercise $(123 \pm 4$ and $134 \pm$ 4 beats/min) was significantly higher than during supine exercise ( $111 \pm 2$ and $114 \pm 4$ beats $/ \mathrm{min})$ $(\mathrm{P}<0.01)$. Systolic blood pressure was similar during the 2 exercise periods (treadmill $P_{1}, 162 \pm 5$, $P_{2}, 168 \pm 6 \mathrm{mmHg}$; supine $P_{1}, 161 \pm 4, P_{2}$, $167 \pm 5 \mathrm{mmHg}$ ). Thus, because of the different heart rates in the 2 postures, higher values for rate pressure product were obtained during treadmill exercise both at $P_{1}\left(203 \pm 9 \mathrm{mmHg} / \mathrm{min} \times 10^{-2}\right)$, and $\mathrm{P}_{2}\left(225 \pm 11 \mathrm{mmHg} / \mathrm{min} \times 10^{-2}\right)$ than during supine bicycle exercise $\left(P_{1} 182 \pm 8, P_{2} 190 \pm 10\right.$ $\left.\mathrm{mmHg} / \mathrm{min} \times 10^{-2}\right)(\mathrm{P}<0.01)$ (Fig. 2).

\section{STUDIES AFTER GLYCERYL TRINITRATE}

(Table 2)

At rest after glyceryl trinitrate, there was a significant decrease in systolic blood pressure $(P<0.01)$, and increase in heart rate $(P<0.001)$ from the control values in both the postures.

During both the treadmill and supine exercise after glyceryl trinitrate administration, all patients developed angina $\left(\mathbf{P}_{1}\right)$, while moderately severe angina $\left(\mathrm{P}_{2}\right)$ was experienced by 14 patients during treadmill exercise and by 12 patients during supine bicycle exercise. In the patients who did not experience $\mathrm{P}_{2}$ after glyceryl trinitrate, exercise was discontinued primarily because of fatigue. The duration of exercise after glyceryl trinitrate to $P_{1}$ increased in all but 1 patient from the control values during each mode of exercise (Fig. 1). The average values for exercise duration after glyceryl trinitrate increased significantly from the control values during treadmill ( $433 \pm 46 \mathrm{~s}$ vs $288 \pm 35 \mathrm{~s}, \mathrm{P}<0.01)$ and supine bicycle exercise $(450 \pm 56 \mathrm{~s}$ vs $240 \pm 29 \mathrm{~s}$, $P<0.01$ ) (Fig. 1).

Since every patient did not experience $P_{2}$ after 
Table 2 Summary of circulatory and electrocardiographic data before and after glyceryl trinitrate

\begin{tabular}{|c|c|c|c|c|c|}
\hline \multirow[t]{2}{*}{ State } & \multirow[t]{2}{*}{$\begin{array}{l}\text { Heart rate } \\
\text { (beats } / \text { min) }\end{array}$} & \multicolumn{2}{|c|}{$\begin{array}{l}\text { Blood pressure } \\
(\mathrm{mmHg})\end{array}$} & \multirow[t]{2}{*}{$\begin{array}{l}\text { Rate pressure product } \\
\left(\mathrm{mmHg} / \min \times 10^{-2}\right)\end{array}$} & \multirow[t]{2}{*}{$\underset{(\mathrm{mm})}{E C G} S T$ depression } \\
\hline & & Systolic & Diastolic & & \\
\hline \multicolumn{6}{|l|}{ Standing } \\
\hline $\begin{array}{l}\text { C Rest } \\
\text { C Ex } P_{1} \\
\text { C Ex } P_{2} \\
\text { GTN Rest } \\
\text { GTN Ex }\left(C_{1}\right) \\
\text { GTN Ex } P_{1} \\
\text { GTN Ex } P_{2}\end{array}$ & $\begin{aligned} & 83 \pm 3 \\
& 124 \pm 4 \\
& 134 \pm 4 \\
& 109 \pm 4^{\star} \\
& 126 \pm 4 \\
& 144 \pm 4^{\star} \\
& 147 \pm 4^{\star}\end{aligned}$ & $\begin{aligned} 127 & \pm 3 \\
162 & \pm 5 \\
168 & \pm 6 \\
92 & \pm 4^{\star} \\
151 & \pm 5 \\
167 & \pm 6 \\
167 & \pm 6\end{aligned}$ & $\begin{array}{l}84 \pm 2 \\
79 \pm 3 \\
79 \pm 3 \\
70 \pm 3 \star \\
72 \pm 4 \\
74 \pm 3 \\
79 \pm 4\end{array}$ & $\begin{array}{l}105 \pm 5 \\
203 \pm 9 \\
225 \pm 11 \\
100 \pm 5 \\
192 \pm 10 \\
242 \pm 14^{\star} \\
248 \pm 13^{\star}\end{array}$ & $\begin{array}{l}0.0 \pm 0.0 \\
1.3 \pm 0.1 \\
1.7 \pm 0.1 \\
0.0 \pm 0.0 \\
0.5 \pm 0.1 \star \\
1 \cdot 2 \pm 0.1 \\
1.5 \pm 0.1\end{array}$ \\
\hline Supine & & & & & \\
\hline $\begin{array}{l}\text { C Rest } \\
\text { C Ex } P_{1} \\
\text { C Ex } P_{2} \\
\text { GTN Rest } \\
\text { GTN Ex }\left(C P_{1}\right) \\
\text { GTN Ex } P_{1} \\
\text { GTN Ex } P_{2}\end{array}$ & $\begin{array}{r}73 \pm 3 \\
111 \pm 2 \\
114 \pm 4 \\
85 \pm 3^{\star} \\
112 \pm 4 \\
119 \pm 7^{\star} \\
127 \pm 4^{\star}\end{array}$ & $\begin{array}{l}126 \pm 3 \\
161 \pm 4 \\
167 \pm 5 \\
118 \pm 3^{\star} \\
165 \pm 4 \\
181 \pm 6^{\star} \\
185 \pm 5^{\star}\end{array}$ & $\begin{array}{l}81 \pm 2 \\
86 \pm 3 \\
85 \pm 3 \\
81 \pm 3 \\
83 \pm 3 \\
84 \pm 3 \\
86 \pm 4\end{array}$ & $\begin{aligned} 89 & \pm 4 \\
182 & \pm 8 \\
190 & \pm 10 \\
97 & \pm 4 \\
185 & \pm 9 \\
230 & \pm 11^{\star} \\
235 & \pm 11^{\star}\end{aligned}$ & $\begin{array}{l}0.0 \pm 0.0 \\
1.1 \pm 0.1 \\
1.3 \pm 0.1 \\
0.0 \pm 0.0 \\
0.8 \pm 0.1 \star \\
1.0 \pm 0.1 \\
1.1 \pm 0.2\end{array}$ \\
\hline
\end{tabular}

Data presented as mean \pm standard error of the mean.

Abbrevations: $C$, average of 2 control studies 1 and 2 ; Ex, exercise; GTN, glyceryl trinitrate; GTN Ex (CP $)$, identical work loads as during control studies at $\mathbf{P}_{1} ; \mathbf{P}_{1}$, onset of chest pain; $\mathbf{P}_{2}$, moderately severe chest pain; ${ }^{\star} \mathbf{P}<0.01$ in comparison with the corresponding control values.

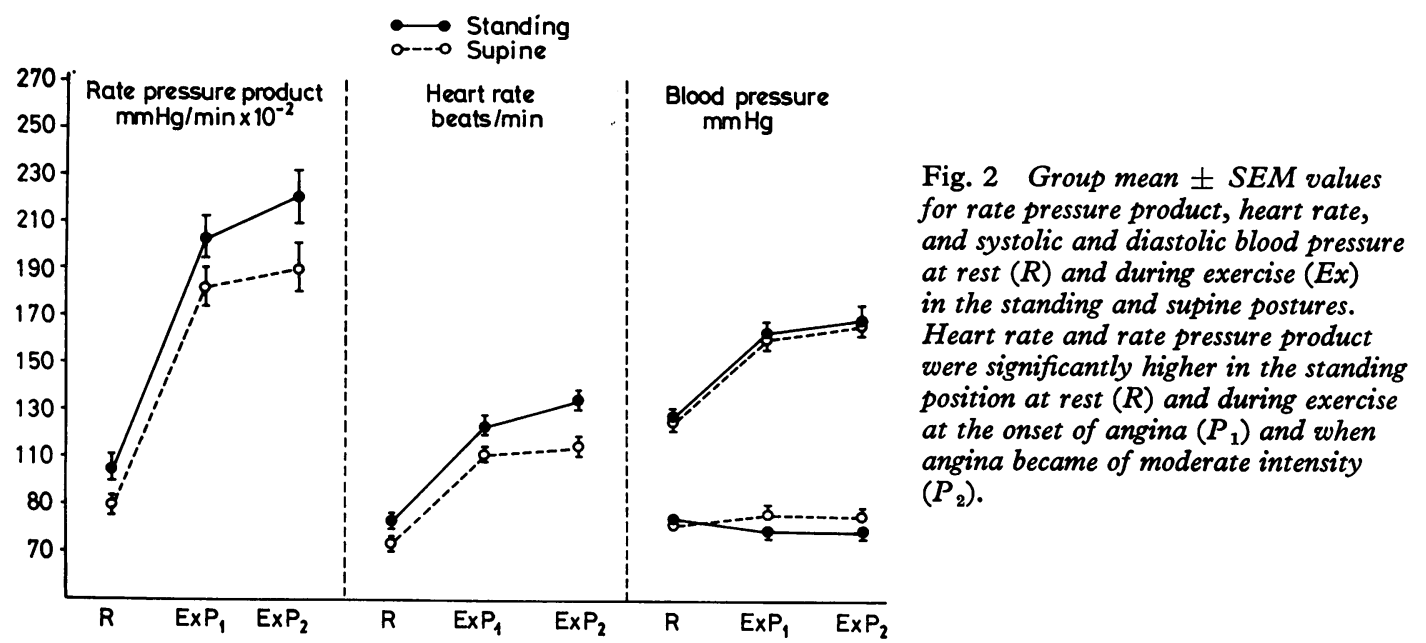

glyceryl trinitrate administration, the exercise duration to fatigue was substituted for $\mathrm{P}_{2}$ and the group values so obtained were compared with control readings at $\mathbf{P}_{2}$. Thus, after glyceryl trinitrate at $\mathbf{P}_{2}$, exercise tolerance was significantly increased in each posture (treadmill, $462 \pm 43 \mathrm{~s}$ vs $357 \pm 35 \mathrm{~s}$, $P<0.01$ ); (supine, $500 \pm 57 \mathrm{~s}$ vs $297 \pm 33 \mathrm{~s}$, $P<0.001$ ).

In comparison with the control studies, the majority of patients exercised to higher work loads after glyceryl trinitrate administration in each posture. Thus, the individual and group values for rate pressure product at $\mathbf{P}_{1}$ after glyceryl trinitrate were significantly higher than the control values at $P_{1}$ during the two modes of exercise (treadmill,
$242 \pm 14$ vs $203 \pm 9 \mathrm{mmHg} / \mathrm{min} \times 10^{-2}, \mathrm{P}<$ 0.001 ; supine, $230 \pm 11$ vs $182 \pm 8 \mathrm{mmHg} / \mathrm{min} \times$ $10^{-2}, P<0.001$ ) (Fig. 3a and b). The increase in rate pressure product during treadmill exercise was the result of a higher heart rate $(144 \pm 4$ vs $123 \pm$ 4 beats $/ \min , P<0.001$ ) while the systolic blood pressure was similar to the control values $(167 \pm 6$ vs $162 \pm 5 \mathrm{mmHg}$ ) (Fig. 3a). In the supine position after glyceryl trinitrate, the increase in rate pressure product was the result of both a higher heart rate (119 \pm 7 vs $111 \pm 2, P<0.001)$, and systolic blood ? pressure $(181 \pm 6$ vs $161 \pm 4, P<0.001)$, than during the control exercise period (Fig. 3b). ST depression at $\mathbf{P}_{1}$ was similar before and after glyceryl trinitrate (Fig. 4). 

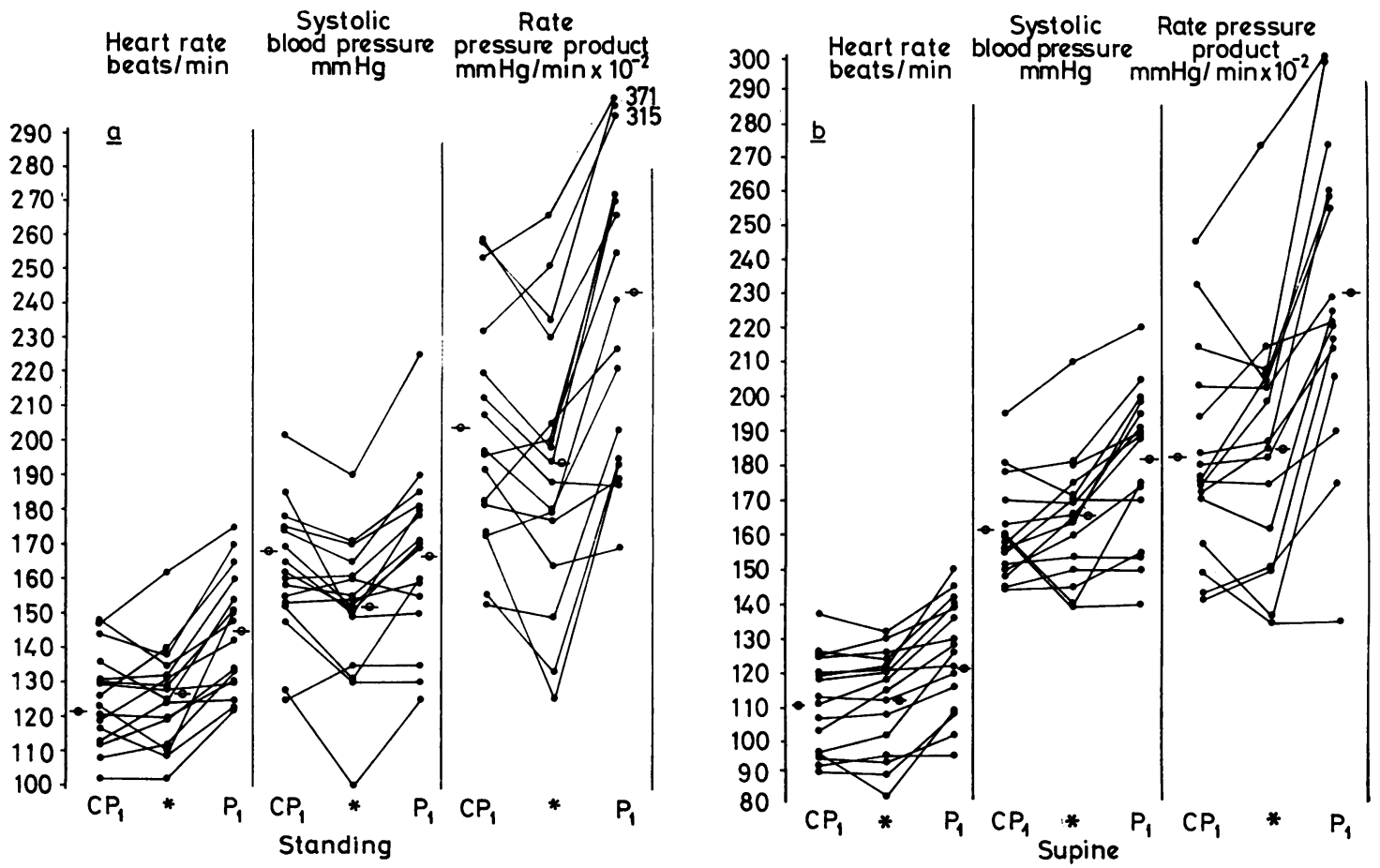

Fig. 3a and b Individual $(\bullet)$ and group mean $(\bullet)$ values for heart rate, systolic blood pressure, and rate pressure product before and after administration of glyceryl trinitrate. In both postures, at the onset of chest pain $\left(P_{1}\right)$ rate pressure product increased significantly after glyceryl trinitrate in comparison with the control $(C)$ values. The increase in rate pressure product was due to higher heart rate during standing exercise and both the higher heart rate and systolic blood pressure during supine exercise. However, at the same work loads $\left({ }^{*}\right)$ after glyceryl trinitrate, there was no significant change in rate pressure product after glyceryl trinitrate in comparison with the values at $P_{1}$, during the control $(C)$ studies in either posture before glyceryl trinitrate.

The values for rate pressure product at $P_{2}$ after glyceryl trinitrate were also significantly higher than the values during exercise before glyceryl trinitrate in the two positions (treadmill, $248 \pm 13$ vs $225 \pm$ $11 \mathrm{mmHg} / \mathrm{min} \times 10^{-2}, \mathrm{P}<0.001$; supine, $235 \pm$ 11 vs $\left.190 \pm 10 \mathrm{mmHg} / \mathrm{min} \times 10^{-2}, \mathrm{P}<0.001\right)$. Again these differences were the result of higher heart rate in the upright position and of both a higher heart rate and systolic blood pressure during supine exercise.

Despite the fact that in the control studies patients could exercise to a higher rate pressure product in the upright posture, after glyceryl trinitrate, the increase in rate pressure product seen during exercise was similar in each position.

While the rate pressure product at the onset of angina $\left(\mathbf{P}_{1}\right)$ was higher after glyceryl trinitrate in each position, it was observed that at the same work load the group mean rate pressure products were similar before and after glyceryl trinitrate (Fig. 3a and $b$ ). Thus, when the rate pressure product at
$P_{1}$ before glyceryl trinitrate was compared with the rate pressure product at the same work load after glyceryl trinitrate, there was no significant difference in either position (treadmill, $192 \pm 10$ vs $203 \pm 9$; supine, $185 \pm 9$ vs $182 \pm 8 \mathrm{mmHg} / \mathrm{min} \times 10^{-2}$ ). Examination of individual values of rate pressure products at identical work loads before and after glyceryl trinitrate showed that the values were lower in 11 during treadmill exercise and in 5 patients during supine bicycle exercise after administration of glyceryl trinitrate. At this time, ST segment depression was less after glyceryl trinitrate than the control values (treadmill, $0.5 \pm 0.1$ vs $1.3 \pm 0.1 \mathrm{~mm}$; supine $0.8 \pm 0.1$ vs $1.1 \pm 0.1 \mathrm{~mm})(P<0.05)$ (Fig. 4).

\section{Discussion}

The present study shows that patients with coronary artery disease were able to exercise to higher rate pressure products at angina in the upright posture 


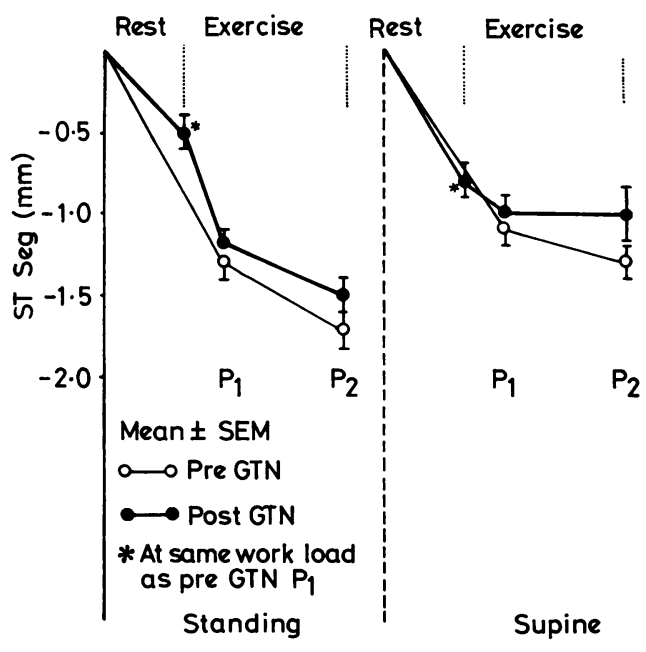

Fig. 4 Changes in $S T$ segment depression from rest to exercise during mild $\left(P_{1}\right)$ and moderate $\left(P_{2}\right)$ angina. In each posture at the same work loads, ST segment depression was significantly reduced after glyceryl trinitrate $(G T N)$ in comparison with the values at $P_{1}$ during studies before glyceryl trinitrate.

than in the supine position. Despite these postural differences, sublingual glyceryl trinitrate increased exercise tolerance and rate pressure product at the onset of angina by a similar degree in both positions.

Before the above results can be put into proper perspective, the methods used must be considered. Measurement of blood pressure by sphygmomanometry rather than by direct arterial cannulation could have introduced errors, but all determinations were made by the same observer and each patient acted as his own control. In the present study, blood pressure recordings during rest and exercise by sphygmomanometry were reproducible during the control studies in each patient. The noninvasive measurement of blood pressure is the only practical way in studies such as this where repeated observations are performed on different days. A close approximation has been documented between systemic arterial pressure recorded by arterial cannulation and sphygmomanometry (Nelson et al., 1974; Clausen and Trap-Jensen, 1976).

It has been reported that normal subjects can exercise to similar work loads and heart rates during exercise in the supine and upright positions (Bevegård et al., 1960, 1963; Epstein et al., 1969). In contrast to this, in the present study, patients with coronary artery disease were able to exercise to higher heart rates and rate pressure products in the upright posture before the onset of chest pain. These findings are in agreement with three previous reports (Lecerof, 1971; Bygdeman and Wahren,
1974; Thadani et al., 1977). On the other hand, $\overrightarrow{\vec{c}}$ Robinson (1967) reported that patients with coronary artery disease invariably experienced angina at constant heart rate and systolic blood pressure products. Robinson (1967) also reported that in some $\vec{d}$ situations it was necessary to correct the rate pressure product for changes in the systolic ejection period, and he found that in the upright position $\vec{\circ}$ angina occurred in each individual at a constant $\overrightarrow{\vec{\omega}}$ corrected rate pressure product despite different $\stackrel{\rho}{\omega}$ modes of exercise. Robinson (1967), however, did not compare the uncorrected or corrected rate pressure product at angina in the supine and upright postures as was done in the present study. We did not measure the ejection period in the present study $\vec{N}$ and hence have not made corrections for this, but $\mathcal{C}$ Bygdeman and Wahren (1974) reported that both $ᄋ$ the rate pressure product and triple product at angina were significantly higher during sitting than supine bicycle exercise.

Before considering the possible mechanisms responsible for the differences in exercise tolerance and rate pressure product at angina during exercise in the supine and upright postures, it is important to examine the pathophysiology of angina and myocardial ischaemia. In patients with coronary artery disease, angina pectoris occurs when the myocardial oxygen demand exceeds oxygen supply. The three important haemodynamic variables directly related to myocardial oxygen requirements are: (1) intramyocardial tension (a function of ventricular systolic pressure, radius, and wall thickness), (2) heart rate, and (3) the contractile state of the ventricle (Sarnoff et al., 1958; Sonnenblick et al., 1965; Boerth et al., 1969). Interplay of these factors determines the net oxygen demand.

There is evidence to suggest that in normal subjects both at rest and during exercise, the heart volume is smaller in the sitting than in the supine posture (Holmgren and Ovenfors, 1960). Furthermore, the results from our laboratory have shown 0 that in patients with coronary artery disease, left ventricular filling pressures were significantly lower during sitting than supine bicycle exercise at the onset of angina (Thadani et al., 1977). It is therefore 0 probable that the higher rate pressure product $N$ achieved during upright exercise at the onset of $\mathcal{W}_{\mathbf{W}}$ angina is the result of decreased ventricular volume $O$ which is a major determinant of intramyocardial tension.

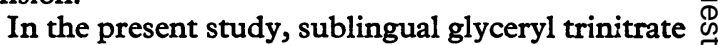
resulted in more distinct reduction in resting systolic blood pressure in the standing than in the supine position. This was responsible for a more pronounced reflex increase in heart rate in the standing position. However, during exercise, 
glyceryl trinitrate resulted in a similar increase in exercise tolerance and rate pressure product at angina in the two postures. Previous reports on the effect of glyceryl trinitrate on rate pressure product at angina have been variable. Robinson (1968) and Clausen and Trap-Jensen (1976) reported that rate pressure product at angina was similar before and after sublingual triglyceryl trinitrate. However, Detry and Bruce (1971) and Goldstein et al. (1971) reported the rate pressure product at angina to be significantly higher than during exercise before glyceryl trinitrate. In the present study and in that of Detry and Bruce (1971), blood pressure was measured by sphygmomanometry, but Robinson (1968) and Goldstein and colleagues (1971) recorded the blood pressure by direct intra-arterial cannulation. It is, therefore, unlikely that this reported discrepancy in rate pressure product at angina after glyceryl trinitrate is the result of different methods used for recording the blood pressure in the different studies.

Rate pressure product does not take ejection time into consideration. Robinson (1968) and Goldstein and colleagues (1971) compared the triple product of heart rate, systolic blood pressure, and ejection time at angina before and after glyceryl trinitrate and reported no change in this product after glyceryl trinitrate. However, other workers have shown that the rate pressure product and heart rate alone are better correlates of oxygen consumption than either the tension time index or triple product, especially after drug intervention (Kitamura et al., 1972; Jorgensen et al., 1973; Nelson et al., 1974). In the present study, after glyceryl trinitrate, the rate pressure product and heart rates were similar to control values at identical work loads but as the majority of patients exercised to higher work loads after glyceryl trinitrate before experiencing angina, this product was significantly higher at angina after glyceryl trinitrate. The increase in rate pressure product at angina after glyceryl trinitrate during treadmill exercise was primarily the result of the higher heart rate, while during supine exercise the increase in this product was caused by both higher heart rate and systolic blood pressure.

Heart rate and systolic blood pressure are important determinants of myocardial oxygen requirements but these two variables do not take into account the influence of ventricular volume and myocardial contractility, factors that are important determinants of myocardial oxygen requirements. In the present study, similar rate pressure products were reached during exercise at identical work loads before and after glyceryl trinitrate. However, when exercise was continued to angina, the rate pressure product at this point was greater than at angina before glyceryl trinitrate administration. This improvement in exercise tolerance after glyceryl trinitrate could be the result of either (1) improved coronary perfusion to ischaemic myocardial zones or (2) diminished left ventricular volume which would reduce ventricular wall tension and myocardial oxygen demand for a given rate pressure product.

The effects of glyceryl trinitrate on the distribution of coronary blood flow in man remains uncertain. In normal subjects, this drug has been shown to increase coronary blood flow by reducing impedance to coronary flow but in patients with obstructive lesions in the coronary arteries, the majority of the studies have failed to show an increase in coronary flow in the diseased vessels (Gorlin et al., 1959). On the other hand, glyceryl trinitrate has been shown to increase the collateral blood flow to the ischaemic myocardium (Forman et al., 1973; Goldstein et al., 1974). However, at times this drug may aggravate ischaemia through a steal phenomenon (Rowe, 1970). The effects of glyceryl trinitrate on left ventricular volume have been more consistent. The drug, by its effects on venous and arteriolar dilatation, reduces resting ventricular volume in both the supine and upright postures (Williams et al., 1965; Hoeschen et al., 1966; Burggraf and Parker, 1974). In a recent echocardiographic study, glyceryl trinitrate reduced ventricular volume during sitting bicycle exercise (Goldstein et al., 1977). Glyceryl trinitrate consistently reduces left ventricular diastolic pressure at rest and during exercise (Parker et al., 1971), and this should facilitate subendocardial perfusion.

Although one might expect the upright posture to be associated with greater changes in left ventricular volume, the improvement in exercise tolerance and increase in rate pressure product after glyceryl trinitrate were similar during both upright and supine exercise. This could be interpreted as evidence for the predominant influence of glyceryl trinitrate on coronary perfusion but it is possible that similar changes in ventricular volume occurred in both positions. The design of the present noninvasive study does not permit us to differentiate the importance of these mechanisms.

\section{References}

Bevegård, S., Holmgren, A., and Jonsson, B. (1960). The effect of body position on the circulation at rest and during exercise with special reference to the influence on stroke volume. Acta Physiologica Scandinavica, 49, 279-298.

Bevegård, S., Holmgren, A., and Jonsson, B. (1963). Circulatory studies in well trained athletes at rest and during heavy exercise, with special reference to stroke volume and the influence of body position. Acta Physiologica Scandinavica, 57, 26-50. 
Boerth, R. C., Covell, J. W., Pool, P. E., and Ross, J., Jr (1969). Increased myocardial oxygen consumption and contractile state associated with increased heart rate in dogs. Circulation Research, 24, 725-734.

Bruce, R. A. (1971). Exercise testing of patients with coronary artery disease. Annals of Clinical Research, 3, 323-332.

Burggraf, G. W., and Parker, J. O. (1974). Left ventricular volume changes after amyl nitrite and nitroglycerin in man as measured by ultrasound. Circulation, 49, 136-143.

Bygdeman, S., and Wahren, J. (1974). Influence of body position on the anginal threshold during leg exercise. European fournal of Clinical Investigation, 4, 201-206.

Clausen, J. P., and Trap-Jensen, J. (1976). Heart rate and arterial blood pressure during exercise in patients with angina pectoris. Effects of training and of nitroglycerin. Circulation, 53, 436-442.

Detry, J. M. R., and Bruce, R. A. (1971). Effects of nitroglycerin on 'maximal' oxygen intake and exercise electrocardiogram in coronary artery disease. Circulation, 43, 155-163.

Epstein, S. E., Beiser, G. D., Stampfer, M., and Braunwald, E. (1969). Exercise in patients with heart disease. Effects of body position and type and intensity of exercise. American fournal of Cardiology, 23, 572-576.

Forman, R., Kirk, E. S., Downey, J. M., and Sonnenblick, E. M. (1973). Nitroglycerin and heterogeneity of myocardial blood flow. Fournal of Clinical Investigation, $\mathbf{5 2}$ 905-911.

Goldstein, R. E., Bennet, D., and Leech, G. L. (1977). Effects of nitroglycerin on echocardiographic left ventricular dimensions during upright exercise (abstract). American fournal of Cardiology, 39, 289.

Goldstein, R. E., Rosing, D. R., Redwood, D. R., Beiser, C. D., and Epstein, S. E. (1971). Clinical and circulatory effects of isosorbide dinitrate: comparison with nitroglycerin. Circulation, 43, 629-640.

Goldstein, R. E., Stinson, E. B., Scherer, J. L., Seningen, R. P., Grehl, T. M., and Epstein, S. E. (1974). Intraoperative coronary collateral function in patients with coronary occlusive disease. Circulation, 49, 298-308.

Gorlin, R., Brachfeld, N., MacLeod, C., and Bopp, P. (1959). Effect of nitroglycerin on the coronary circulation in patients with coronary artery disease or increased left ventricular work. Circulation, 19, 705-718.

Hoeschen, R. J., Bousvaros, G. A., Klassen, G. A., Fam, W. M., and McGregor, M. (1966). Haemodynamic effects of angina pectoris and of nitroglycerin in normal and anginal subjects. British Heart fournal, 28, 221-230.

Holmgren, A., and Ovenfors, C. L. (1960). Heart volume at rest and during muscular work in the supine and in the sitting position. Acta Medica Scandinavica, 167, 267-277.

Jorgensen, C. R., Wang, K., Wang, Y., Gobel, F. L., Nelson,

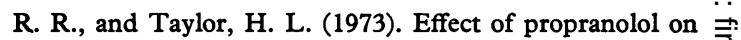
myocardial oxygen consumption and its hemodynamic $\stackrel{\oplus}{\rightarrow}$ correlates during upright exercise. Circulation, 48, 11731182.

Kitamura, K., Jorgensen, C. R., Gobel, F. L., Taylor, H. L., and Wang, Y. (1972). Hemodynamic correlates of myocardial oxygen consumption during upright exercise. Fournal of Applied Physiology, 32, 516-522.

Lecerof, $H$. (1971). Influence of body position on exercise tolerance, heart rate, blood pressure, and respiratory rate in coronary insufficiency. British Heart fournal, 33, 78-83.

Mason, D. T., and Braunwald, E. (1965). The effects of nitroglycerin and amyl nitrate on arteriolar and venous tone in the human forearm. Circulation, 32, 755-766.

Nelson, R. R., Gobel, F. L., Jorgensen, C. R., Wang, K., Wang, Y., and Taylor, H. L. (1974). Hemodynamic predictors of myocardial oxygen consumption during static and dynamic exercise. Circulation, 50, 1179-1189.

Parker, J. O., West, R. O., and Di Giorgi, S. (1971). The effect of nitroglycerin on coronary blood flow and the hemodynamic response to exercise in coronary artery disease. American fournal of Cardiology, 27, 59-65.

Robinson, B. F. (1967). Relation of heart rate and systolic blood pressure to the onset of pain in angina pectoris. Circulation, 35, 1073-1083.

Robinson, B. F. (1968). Mode of action of nitroglycerin in angina pectoris. British Heart fournal, 30, 295-302.

Rowe, G. G. (1970). Inequalities of myocardial perfusion in coronary artery disease ('coronary steal'). Circulation, 42, 193-194.

Sarnoff, S. J., Braunwald, E., Welch, G. H., Jr., Case, R. B., Stainsby, W. N., and MacRuz, R. (1958). Hemodynamic determinants of oxygen consumption of the heart with special reference to the tension time index. American Fournal of Physiology, 192, 148-156.

Sonnenblick, E.H., Ross, J., Jr., Covell, J. W., Kaiser, G. A., and Braunwald, E. (1965). Velocity of contraction as a determinant of myocardial oxygen consumption. American fournal of Physiology, 209, 919-927.

Thadani, U., West, R. O., Mathew, M. T., and Parker, J. O. (1977). Hemodynamics at rest and during supine and sitting bicycle exercise in patients with coronary artery disease. American fournal of Cardiology, 39, 776-783.

Williams, J. R., Jr., Glick, G., and Braunwald, E. (1965) Studies on cardiac dimensions in intact unanesthetized man. V. Effects of nitroglycerin. Circulation, 32, 767-771.

Requests for reprints to Dr Udho Thadani, Ftherington Hall, Queen's University, Kingston, Ontario, Canada. 